Check for updates

The BMJ

Cite this as: BMJ 2021;373:n1452 http://dx.doi.org/10.1136/bmj.n1452 Published: 07 June 2021

\section{Sixty seconds on ... cough in a box}

Abi Rimmer

\section{Sounds like a terrible gift}

Don't worry, we're not talking about wrapping up covid symptoms. This is the news that the UK government is looking into whether artificial intelligence (AI) can be used to detect covid-19 by analysing the sound of someone's cough.

\section{And the box?}

I'm not quite sure where that fits in. The website Politico, which first reported the story, said that the Department of Health and Social Care has awarded two deals to Japanese tech firm Fujitsu to help it build an online "cough in a box" platform. ${ }^{1}$

\section{A what?}

The health department said that the Joint Biosecurity Centre is working with the Alan Turing Institute and the Royal Statistical Society to assess the feasibility of "applying algorithms to detect covid-19 based on vocal biomarkers including coughing."

\section{So they listen to coughs?}

Essentially, yes. In a paper published in the IEEE Journal of Engineering in Medicine and Biology ${ }^{2}$ last year, a team of researchers from the Massachusetts Institute of Technology (MIT) in the US described an AI model they had developed which distinguishes the coughs of healthy patients from those with covid-19.

\section{Do I cough on a machine?}

No, the MIT researchers used forced cough recordings, which people voluntarily submitted through web browsers from their mobile phones and laptops. ${ }^{3}$ Before the pandemic, the researchers had been developing algorithms to diagnose conditions such as pneumonia and asthma from phone recordings of coughs.

\section{So maybe it's a phone box?}

Clever, but the technology is far more advanced than that. According to Politico, cough in a box will be a web platform that can collect audio recordings and be linked to QR codes of the kind used by the UK's covid-19 app.

\section{Futuristic!}

The health department seems to hope so. Commenting on the plans, it said that the UK "is at the forefront of innovative research to expand our collective understanding of covid-19.”

Honeycomb-Foster M. UK mulls using Al to check coughs for coronavirus. 3 June 2021. www.politico.eu/article/uk-ai-coughs-coronavirus-fujitsu.

Laguarta J, Hueto F, Subirana B. Covid-19 artificial intelligence diagnosis using only cough recordings. IEEE Open Journal of Engineering in Medicine and Biology. 2020;1:275-81. https://ieeexplore.ieee.org/document/9208795

3 Chu J. Artificial intelligence model detects asymptomatic covid-19 infections through cellphone-recorded coughs. Massachusetts Institute of Technology news office. 2020. https://news.mit.edu/2020/covid-19-cough-cellphone-detection-1029. 